ISBN 978-93-84468-86-6

2016 International Research Conference on Social Sciences, Humanities and Interdisciplinary Studies

(RCSSHIS-2016)

Pattaya (Thailand) Dec. 16-17, 2016

\title{
Performance Motivation Development of Smart Land Asset Co., Ltd. Employees in Bangkok
}

\author{
Assoc. Prof. Suthum Pongsamran, and SophonChonpannon \\ planning@kbu.ac.th \\ Post gaduate school of Business Administration \\ Kasembundit University, Bangkok
}

\begin{abstract}
The purpose of this study was to determine factors of performance motivation development of Smart Land Asset Co., Ltd., Group. Samplings from this study were 85 Smart Land Asset Co., Ltd., Group employees by using questionnaire as a tool. The statistic applications used for this study were percentage, mean, standard deviation, t-test, One-way Anova, and regression analysis.Findings indicated that most of respondents were females, age between 31-40 years old, single and marriages status, earned less than bachelor degree education, average monthly income less than 20,000 baht, and 1-5 years working experience. The average picture of opinions regarding factors of performance motivation were in the high level consisted of work description, job responsibility, career advancement, job completion, company policy and employee management, work environment, relationship with coworkers and supervisors, quality of work life, and job security were in the high level, however career advancement, receive recognition, and salary aspects were in medium level. Hypothesis testing revealed that the factors of motivation, receive recognition, job completion, employees management, salary, work environment, and coworkers relationship were related to Smart Land Asset Co., Ltd., Group employees satisfaction with statistical significant at 0.05 level.

Recommendations from this study were that administrative officers should open to employees' discussion, opinion and involve in decision making, create social event for company employees, suitable work environment, and adjust income to meet with current living expenses in order to maintain performance motivation for Smart Land Asset Co., Ltd., Group employees.
\end{abstract}

Keywords: motivate development

\section{Introduction}

All businesses in the present economy, the competition has been escalating, various techniques and strategies have been implemented in order to become the leader in business, create competitive advantage in the marketplace, andmanage to the changing business condition. Therefore, companies need to adjust the process of operations, such as human resources development includes such opportunities as employee training, employee career development, performance management and development, coaching, mentoring, succession planning, key employee identification, organization development, system development in modern technology,and modify the internal management systems within the organization. Organizations have proven that the human resources are the most important in all businesses asset. Executive officers must proceeds into account of the importance of employee motivation and morale.Smart Land Asset Co., Ltd.has been observed the operational behavior of the company employees in the past years and found that employees turned over rate approximately 40 percent of all company employees,as a result of the economic crisis and hired by rival companies. Such issues company can resolve turn over problem by creating incentives to workers as of the motivation in practice neither depend on any one factor, but it depends on many factors, each factor are affected differently, one factor might be the most important to an employee or a group of employees in different environment and culture, appropriate job 
description may stimulates and enables collaboration, including responsibilities and achievements to get dignified may be able to overcome the problem. In contrast, employees dissatisfaction in the company policy, unhealthy work environmentwhich finding anunfavorable solutionwill deterioratein work practices.

\section{Significance of the study}

Therefore, researcher haveconsiderate and foreseen benefits from this approach in the development of a system of staff to accomplish goals. Theresearcher, a general manager position of Smart Land Asset Co., Ltd.Group whoseworks related to the management and development of employee potential.The purpose of this study was to determine factors of performance motivation development of Smart Land Asset Co., Ltd., Groupemployees.To recommend the findings to Smart Land Asset Co., Ltd., for future human resources development.

Literature review

Two-factor theory and concepts of Frederick Herzberg's Two-Factor Theory

Two-factor theory distinguishes between:

1. Motivators (e.g. challenging work, recognition for one's achievement, responsibility, opportunity to do something meaningful, involvement in decision making, sense of importance to an organization) that give positive satisfaction, arising from intrinsic conditions of the job itself, such as recognition, achievement, or personal growth, and

2. Hygiene factors (e.g. status, job security, salary, fringe benefits, work conditions, good pay, paid insurance, vacations) that do not give positive satisfaction or lead to higher motivation, though dissatisfaction results from their absence. The term "hygiene" is used in the sense that these are maintenance factors. These are extrinsic to the work itself, and include aspects such as company policies, supervisory practices, or wages/salary. Herzberg often referred to hygiene factors as "KITA" factors, which is an acronym for "kick in the ass", the process of providing incentives or threat of punishment to make someone do something.

According to Herzberg, hygiene factors are what causes dissatisfaction among employees in a workplace. In order to remove dissatisfaction in a work environment, these hygiene factors must be eliminated. There are several ways that this can be done but some of the most important ways to decrease dissatisfaction would be to pay reasonable wages, ensure employees job security, and to create a positive culture in the workplace. Herzberg considered the following hygiene factors from highest to lowest importance: company policy, supervision, employee's relationship with their boss, work conditions, salary, and relationships with peers. Eliminating dissatisfaction is only one half of the task of the two factor theory. The other half would be to increase satisfaction in the workplace. This can be done by improving on motivating factors. Motivation factors are needed to motivate an employee to higher performance. Herzberg also further classified our actions and how and why we do them, for example, if you perform a work related action because you have to then that is classed as "movement", but if you perform a work related action because you want to then that is classed as "motivation". Herzberg thought it was important to eliminate job dissatisfaction before going onto creating conditions for job satisfaction because it would work against each other.

\section{The Purpose of the Study}

The purpose of this study was to determine factors of performance motivation development of Smart Land Asset Co., Ltd., Group.

\section{Frame Work of the Study}



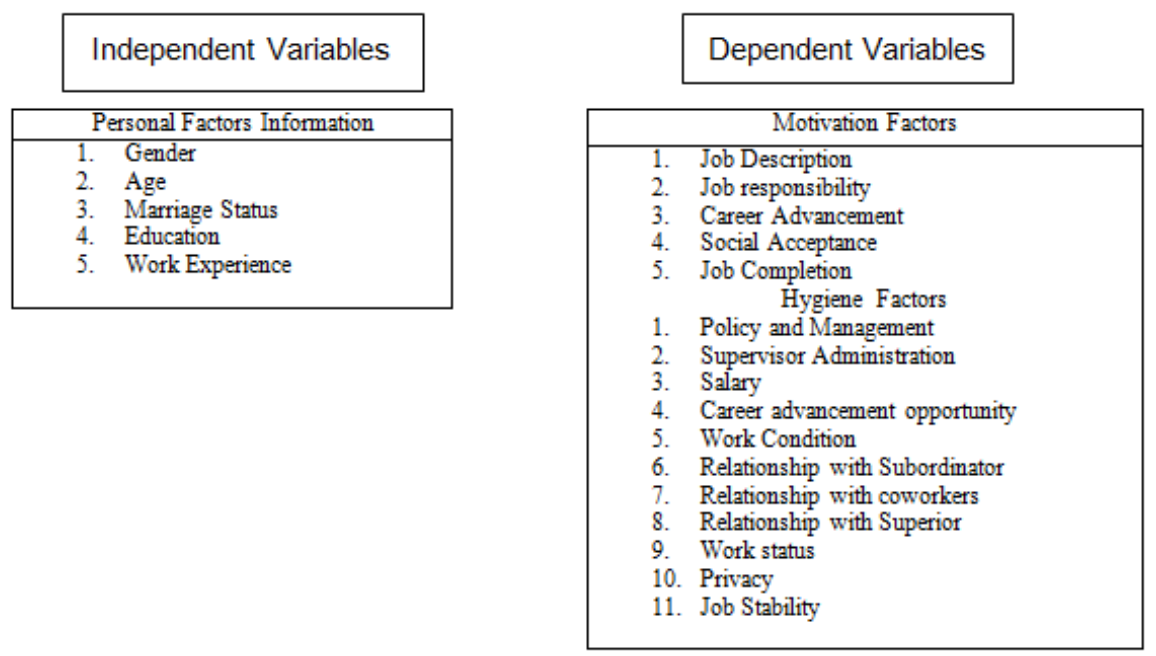

\section{Sample Selection}

Samplings from this study were 85 Smart Land Asset Co., Ltd., Group employees.

\section{Data}

Questionnaires were sent to 104 Smart Land Asset Co., Ltd., group of employees. A total of 85 usable questionnaires were returned back to the researcher, yielding a95 percent response rate. A check for missing data was conducted since some questionnaires were incompletely filled. Since missing data was less than 10 percent of the data for any single variable, they were replaced with the column mean (Little \& Rubin, 2002).

TABLEI shows results comparing the factors affecting the motivation, satisfaction in the performance of Smart Land Asset Co., Ltd., group of employees classified by gender

\begin{tabular}{|c|c|c|c|c|c|c|}
\hline Gender & Mean & S.D. & $\mathrm{t}$ & $\mathrm{df}$ & Sig. & Test \\
\hline Male & 3.68 & 0.163 & -0.552 & 83 & 0.882 & No difference \\
\hline Female & 3.77 & 0.163 & & & & \\
\hline
\end{tabular}

Hypothesis testing of the value $\mathrm{t}$ - test at significance level 0.05 established that the factors of motivation towards satisfaction in the work performance of employees Sig. equalto 0.882 which is greater than the level of statistical significance 0.05, accepted main hypotheses H0, interpreted that in Smart Land Asset Co., Ltd., characterized by the gender different was not affected to job performance satisfaction.

TABLE II shows the results of hypotheses testing of variance of employee performance satisfaction atSmart Land Asset Co.,

\begin{tabular}{|c|c|c|c|c|c|c|}
\hline $\begin{array}{c}\text { The important of } \\
\text { motivation factors }\end{array}$ & SS & df & MS & F & Sig. & Test \\
\hline Between Group & .618 & 3 & .206 & .361 & .781 & No difference \\
\hline Within Group & 46.159 & 81 & .570 & & & \\
\hline Total & 46.776 & 84 & & & & \\
\hline
\end{tabular}

The hypothesis testing revealed that the value of the One-Way ANOVA at significance level 0.05, motivation factors affecting the performance satisfaction of the employee at Sig. equal 0.781, which is greater than the level of statistical significance level 0.05, accepted main hypotheses H0,Smart Land Asset Co., Ltd. employees with age different was not affected performance satisfaction.

TABLEIII shows the results of hypotheses testing the variance of performance satisfaction of employeesSmart Land Asset Co., Ltd. classified by marriage status

\begin{tabular}{|c|c|c|c|c|c|c|}
\hline $\begin{array}{c}\text { The important of } \\
\text { motivation factors }\end{array}$ & SS & df & MS & F & Sig. & Test \\
\hline Between Group & 1.089 & 2 & .545 & .978 & .381 & No difference \\
\hline Within Group & 45.687 & 82 & .557 & & & \\
\hline Total & 46.776 & 84 & & & & \\
\hline
\end{tabular}


Test results from the hypotheses by the value of One-Way ANOVA at significance 0.05 level finds that motivation factors are affecting the performance satisfaction of the employee with valuable Sig. equal 0.381, which is more than the statistical significance 0.05 level, accepted main hypotheses H0,Smart Land Asset Co., Ltd. employees with marriage status different was not affected performance satisfaction.

TABLE IV shows the results of hypotheses testing the variance of performance satisfaction of employees Smart Land Asset Co., Ltd. classified by level of education

\begin{tabular}{|c|c|c|c|c|c|c|}
\hline $\begin{array}{c}\text { The important of } \\
\text { motivation factors }\end{array}$ & SS & $\mathrm{df}$ & MS & $\mathrm{F}$ & Sig. & Test \\
\hline Between Group & 3.140 & 2 & 1.570 & 2.950 & .058 & No difference \\
\hline Within Group & 43.637 & 82 & .532 & & & \\
\hline Total & 46.776 & 84 & & & & \\
\hline
\end{tabular}

Test results from the hypotheses by the value of One-Way ANOVA at significance 0.05 level finds that motivation factors are affecting the performance satisfaction of the employee with valuable Sig. equal 0.58 , which is greater than the statistical significance 0.05 level, accepted main hypotheses H0, Smart Land Asset Co., Ltd. employees with level of education different was not affected performance satisfaction.

TABLE V shows the results of hypotheses testing the variance of performance satisfaction of employees Smart Land Asset Co., Ltd. classified by average monthly income

\begin{tabular}{|c|c|c|c|c|c|c|}
\hline $\begin{array}{c}\text { The important of } \\
\text { motivation factors }\end{array}$ & SS & df & MS & F & Sig. & Test \\
\hline Between Group & 2.043 & 3 & .681 & 1.233 & .303 & No difference \\
\hline Within Group & 44.733 & 81 & .552 & & & \\
\hline Total & 46.776 & 84 & & & & \\
\hline
\end{tabular}

Test results from the hypotheses by the value of One-Way ANOVA at significance 0.05 level finds that motivation factors are affecting the performance satisfaction of the employee with valuable Sig. equal 0.58 , which is greater than the statistical significance 0.05 level, accepted main hypotheses H0, Smart Land Asset Co., Ltd. employees with average monthly income different was not affected performance satisfaction.

TABLE VI shows the results of hypotheses testing the variance of performance satisfaction of employees Smart Land Asset Co., Ltd. classified by operational experience

\begin{tabular}{|c|c|c|c|c|c|c|}
\hline $\begin{array}{c}\text { The important of } \\
\text { motivation factors }\end{array}$ & SS & $\mathrm{df}$ & MS & F & Sig. & Test \\
\hline Between Group & 4.898 & 3 & .693 & 1.103 & .129 & No difference \\
\hline Within Group & 41.879 & 81 & .517 & & & \\
\hline Total & 46.776 & 84 & & & & \\
\hline
\end{tabular}

Test results from the hypotheses by the value of One-Way ANOVA at significance 0.05 level finds that motivation factors are affecting the performance satisfaction of the employee with valuable Sig. equal 0.58 , which is greater than the statistical significance 0.05 level, accepted main hypotheses H0, Smart Land Asset Co., Ltd. employees with operational experience different was not affected performance satisfaction.

\section{Conclusion}

Findings indicated that most of 85respondents were females, age between 31-40 years old, single or marriages status, received less than bachelor degree, average monthly income less than 20,000 baht, and 1-5 years working experience.

Results from the study found that the average picture of opinionsof motivation factorsthat affect work performance of employees at Smart Land Asset Co., Ltd., were in high level, consisted of job description, job responsibility, career advancement, social acceptance, job completion, company policy and management, supervisor administration, salary and compensation, career advancement, opportunity, work condition, relationship with subordinator, relationship with coworkers, relationship with superior, work status, privacy, and job stability with details as follows:

1. Suggestions for further study 
Administrative officers should open to employees' discussion, opinion and involve in decision making, create social event for company employees, suitable work environment, and adjust income to meet with current living expenses in order to maintain performance motivation for Smart Land Asset Co., Ltd., group employees.

\section{References}

[1] ChutaratEarumnoy. (2549). Social psychology, ChulalongkornUninversitypublisher, Bangkok

[2] ChukiatYimpoung. (2554). Work Performance Motivation: Case study, Bangkok Glass Co., Ltd., Patumthani Province, Independent study, Master of Business Administration, Ratchamonkok Technology University.

[3] ChutniGlunsorn. (2553). Factors of Performance Motivation of University Personnel, KasetsartUniversity, Sriracha campus, Thesis, Master of Business Administration, Burapha University.

[4] ThongchaiSantivong. (2539). Organization and Management, Bangkok, Thai WattanaPanichPublisher.

[5] TanachaiYomjinda and SanayJuito. (2544). Organization Theory, unit 4, Organization behavior,Teaching documents, Sukho Thai Thammathirach University, Bangkok, department of publishing, Sukho Thai Thammathirach University.

[6] BoonmunThanasuppavat. (2537). Social psychology, Bangkok: Odian Store Publisher.

[7] PhraBoonchanPhakam. (2547). Work Performance Motivation of Executive Officers, Lecturer and University personnel, ChulalongkornRatchavitayalai University, Korn Kean Campus, and Thesis papers, human resouces management, Graduate School, Burapha University.

[8] MunruthaiNiranrat. (2553). Factors of Performance Motivation of Thana Chard Bank, Co., Ltd., $\quad$ Public Personnel, NgarmVong Van branch, Independent Study, Master of Business Administration, Sukho Thai Thammathirach University.

[9] MullikaTonsorn. (2544). Organizational Behavior, Bangkok: Exburnet Co., Ltd.

[10] RoongtivaIntajai. (2553). Performance Motivation of Piyaveth Hospital Co., Ltd. employees, Thesis, Master of Art, National Institute of Development Administration.

[11] RoongnaphaSuwannachard. (2558). Performance Motivation of Eurvithaya Co., Ltd. employees, Independent Study, Master of Business Administration, KasemBundit University.

[12] LattikarnSrivarom. (2541). General Business: fundamental of business practice, Bangkok: Theera Film and Chi tech.

[13] VassanaPattananunchai. (2553). Factors of Performance Motivation of Crown Property BureauPersonnel, Thesis, Master of Art, National Institute of Development Administration.

[14] VoranathSangmanee. (2547). Human Resource Management, $3^{\text {rd }}$ edition, human resource, Bangkok, Prasitphun and Printing.

[15] SirisoparkBurapadecha. (2528). Business Psychology, Bangkok: Chulalongkorn University.

[16] SivapornKeawkum. (2551). Factors of Performance Motivation of Siam Commercial Bank, Co., Ltd., Public company, branch 6, Bangkok, Independent Study, Master of Business Administration,Technology

RatchamongkolRattanakosin University.

[17] SapornSareerat. (2540). Consumer Behavior, $2^{\text {nd }}$ edition, Dorgya Publisher, Bangkok.

[18] SanohTiyao. (2543). Management Principles, Bangkok, Thammasart University Publishing.

[19] SunantaLaohanun. (2541). Human Resource Management, Bangkok, RatchapathSomdejChaopayaInstitute.

[20] SompongKasemsin. (2534). Management, Bangkok, Thai WattanaPanich publishing.

[21] SompornSutassani. (2542). Human Relationship, Chulalongkorn University publishing.

[22] AmornratChukeaw. (2555). Performance Motivation of Ammarit and Associate Co., Ltd., Independent Study, Master of Business Administration, Thaksin University.

[23] Beach, Dale S. (1965). Personnel: Management of People at work. New York:TheMacmillan Co. Ltd.

[24] Davis Keith. (1981). Human Behavior at Work: Organizational Behavior. New York:McGraw-Hill Book Company.

[25] Dubrin. A.J. (1984). Foundation of Organizational Behavior: An Applied Perspective. Englewood Cliffs N.J.: Prentice-Hall.

[26] French. (1982). Organization Development. Experiential approach to organizationDevelopment. (6thed). Englewood Cliffs, New Jersy: Prentice Hall.

[27] Gardon, J. E. (1990). Personality and Behaviours. New York : McMillan.

[28] Gilmer, B.V. (1971). Applied Psychology. New York : McGraw-Hill Book Company.

[29] Herzberg, Frederick; Mausner, Bernard; Snyderman, Barbara B. (1959). The Motivation to Work (2 ${ }^{\text {nd }}$ Ed.). New York: John Wiley. ISBN 0471373893 
[30] Hackman, J. Richard; Oldham, Greg R. (August 1976). "Motivation through the Design of Work: Testof a Theory". Organizational Behavior and Human Performance. 16 (2): 250-279. Doi: 10.1016/0030-5073(76)90016-7. OCLC 4925746330.

https://doi.org/10.1016/0030-5073(76)90016-7

[31] Herzberg, Frederick (January-February 1968). "One More Time: How Do You Motivate Employees?". Harvard Business Review. 46 (1): 53-62. OCLC 219963337.

[32] "Herzberg's Motivation-Hygiene Theory (Two Factor Theory)". NetMBA.com. Retrieved December 9, 2014.

[33] Little, R. J. A., \& Rubin, D.B. (2002). Statistical analysis with missing data (2nd Ed.). Hoboken, N.J.: Wiley. https://doi.org/10.1002/9781119013563

[34] Lock. E.A. (1976). The Nature and Causes of job Satisfaction in Marvin D. Dunnette Edition Handbook of Industrial and Organizational Psychology. Chicago:Ran McNally.

[35] Porter, L. W.,Lawler,E.E,.\& Hackman, J.R. (1967) : Behavior in Organization (4 $4^{\text {th }}$ ed.).New York: McGraw-Hill.

[36] Schiffman, L., \&Kanuk, L. (1994). Consumer Behavior. New Jersey: Prentice Hall.

[37] Vroom, V. H. (1970). Work and Motivation. New York: John Willy \& son.

[38] Yoder, D. and P.D. Staudlhar. (1958) Personnal Management \& Industrial Relations. New Jersey: Prentice-Hall, Inc. 